\title{
The Top End Sleepiness Scale (TESS): A New Tool to Assess Subjective Daytime Sleepiness Among Indigenous Australian Adults
}

This article was published in the following Dove Press journal: Nature and Science of Sleep

\author{
Edmund Benn' \\ Hugh Wirth' \\ Teagan Short' \\ Timothy Howarth (iD) ${ }^{2,3}$ \\ Subash S Heraganahally $\mathbb{D}^{1,3,4}$ \\ 'College of Medicine and Public Health, \\ Flinders University, Adelaide, South \\ Australia, Australia; ${ }^{2}$ College of Health \\ and Human Sciences, Charles Darwin \\ University, Darwin, Northern Territory, \\ Australia; ${ }^{3}$ Darwin Respiratory and Sleep \\ Health, Darwin Private Hospital, Darwin, \\ Northern Territory, Australia; \\ ${ }^{4}$ Department of Respiratory and Sleep \\ Medicine, Royal Darwin Hospital, \\ Darwin, Northern Territory, Australia
}

Correspondence: Subash S Heraganahally Department of Respiratory and Sleep Medicine, Royal Darwin Hospital, Tiwi, Darwin, NT, Australia

Tel +6I-8-89228888

Fax+6I-8-89206309

Email hssubhashcmc@hotmail.com
Purpose: To illustrate the utility of a newly developed culturally safe and clinically relevant subjective daytime sleepiness assessment tool "Top End Sleepiness Scale" (TESS) for use among Indigenous Australians.

Patients and Methods: The TESS questionnaire consists of pictorial representations of 6 items representing daily activities that would induce daytime sleepiness specific for Indigenous Australians living in the regional and remote Australia. Consecutive adult Indigenous patients who consented to pilot the TESS questionnaire prior to undergoing a diagnostic polysomnography (PSG) at the Top End Health Service region, Northern Territory of Australia were assessed. The TESS questionnaire was evaluated for its correlation in predicting obstructive sleep apnea (OSA) according to apnea-hypopnea index.

Results: Eighty-two patients were included. The majority (70\%) had moderate to severe OSA (AHI $\geq 15$ ). Patients were aged in their mid-40's $(45.4795 \%$ CI $(42.9,48.05)$ ) with a tendency to obesity (median BMI 33.67 IQR 30.86, 38.95) and a high prevalence of chronic conditions (72\%) (hypertension, diabetes or heart disease). The TESS showed high internal consistency (Split half Spearman correlation $=0.71$, Cronbach's $\alpha=0.81$ ), and a cutoff value $\geq 3$ resulted in sensitivity $84 \%$, specificity $38 \%$. Comparison of area under the curve for TESS to Epworth Sleepiness Scale (ESS) in this sample showed the TESS to have greater sensitivity and specificity overall, which approached significance $(p=0.072)$ when cut-off values of $\geq 3$ and $\geq 8$ (TESS \& ESS respectively) were used. The sensitivity and specificity for TESS was also comparable to the other currently used questionnaires, such as the Berlin Questionnaire, STOP-BANG and OSA 50.

Conclusion: Currently, there are no subjective daytime sleepiness assessment toll available specifically for Indigenous population. The proposed TESS sleepiness screening tool represented in this study can potentially complement or adopted alongside other existing questionnaire, which may offer greater utility in the assessment of sleep disorders among Indigenous people.

Keywords: First Nations, Aboriginal, Epworth Sleepiness Scale, indigenous, Sleepiness Scale, subjective daytime sleepiness

\section{Plain Language Summary}

It is estimated that there are approximately 370 million people of Indigenous descent worldwide living in over 90 countries who make up five percent of the global population. In the Australian context, about $3.3 \%$ of the population identify as Indigenous Australians. In the Northern Territory of Australia about $30 \%$ of the population identify as Indigenous Australians, and moreover, $81 \%$ of them reside in isolated rural and remote communities. 
Obstructive sleep apnea, a global epidemic, is also being increasingly recognised among Indigenous people. Currently, the Epworth Sleepiness Scale (ESS) is the most common tool utilised in the clinical assessment of subjective daytime sleepiness. However, some parameters in the self-administered ESS questionnaire may not be appropriate or relevant for Indigenous people, especially among those living in isolated regional and remote communities. Hence, there is a desperate need to develop a culturally relevant sleepiness assessment tool specific to Indigenous people. Therefore, we developed and prospectively evaluated a culturally and clinically relevant sleepiness assessment tool, the "Top End Sleepiness Scale" (TESS) and its correlation to apnea-hypopnea index specific to Indigenous Australian patients. The results demonstrated that the TESS tool could be adopted and potentially complement the other currently used sleep assessment tools, such as ESS, Berlin Questionnaire and OSA 50 for Indigenous population.

\section{Introduction}

The prevalence of Obstructive Sleep Apnoea (OSA) in the adult population is reported to be between 6 to $17 \%$ worldwide. $^{1,2}$ OSA can have detrimental effects on individuals' health, being associated with increased all-cause mortality, cardiovascular disease, neurocognitive dysfunction, hypertension, stroke and metabolic syndrome. ${ }^{3-8}$ The burden of chronic health conditions is noted to be higher not only in the Indigenous Australian population, ${ }^{9-12}$ but also amongst other Indigenous people living in the English speaking Organisation for Economic Co-operation and Development (OECD) countries, such as New Zealand Māori's, and First Nations people of Canada and United States of America . ${ }^{13}$ Moreover, occurrence of OSA is being increasingly recognised across diverse ethnic and socioeconomic spectrums, ${ }^{14-16}$ including in the Indigenous Australians and other Indigenous populations globally. ${ }^{17,18}$ Studies have demonstrated that Indigenous people are more likely to return positive results for the presence of OSA in comparison to their non-Indigenous counterparts. ${ }^{17,19}$ Earlier studies from our centre, the Top End Health Service (TEHS), in the Northern Territory (NT) of Australia have documented higher prevalence of OSA among Indigenous Australian people living in the regional and remote communities of NT of Australia. ${ }^{20-24}$

In the clinical assessment of patients presenting with sleep disorders, in particular, OSA, an integral component in day to day clinical practice, specifically, in clinical decision-making at the primary health care level is to assess individuals daytime sleepiness and the Epworth Sleepiness Scale (ESS); Supplementary Material) is a well-established tool that is widely utilised for this purpose. $^{25}$ The ESS has been translated into many languages other than English and has been widely adapted for use in various ethnic populations, including non-driving populations in Peru, India and China. ${ }^{26-30}$ The ESS has also been adapted for use with low literacy populations with pictorial representations of the questionnaire. ${ }^{31}$

Although there is evidence in the literature to suggest that the ESS can be adapted to assess daytime sleepiness in various ethnic and socioeconomic populations, there is to our knowledge no specific tool or adaptation of the ESS for the Indigenous Australian population currently. Moreover, there is limited knowledge of the validity of the ESS among Indigenous populations in general. Some parameters in the self-administered ESS questionnaire may not be appropriate or relevant for Indigenous people, especially among those living in isolated remote and regional locations/communities. Furthermore, the deficiency of the ESS tool in providing a valid assessment of daytime sleepiness in Indigenous Australian populations has been acknowledged in previously published literature. ${ }^{19}$

Currently, the ESS is the only tool available to assess subjective day time sleepiness among Indigenous Australians and other Indigenous populations around the world. Development of a culturally appropriate sleepiness assessment tool specific to Indigenous people will facilitate appropriate clinical assessment and management of OSA among such at risk populations to recommend polysomnography (PSG) testing. Therefore, we developed and prospectively evaluated the utility of a culturally and clinically relevant sleepiness assessment tool, the "Top End Sleepiness Scale" (TESS) specific to Indigenous Australians undergoing a diagnostic PSG in the TEHS region of the NT of Australia.

\section{Methods}

\section{Background and Setting}

This prospective study was conducted at the Respiratory and Sleep service based at the Royal Darwin Hospital (RDH) and Darwin Respiratory and Sleep Health (DRSH), based at Darwin Private Hospital (DPH), a tertiary care, Flinders university affiliated teaching hospital for the TEHS region of the NT of Australia. The population profile of the Top End, NT of Australia consists of about 249,220 people of whom about $30 \%$ are of Indigenous Australian descent (the highest proportion among all Australian States and Territories), living in 
a vast geographical area stretched over $245,000 \mathrm{~km}^{2}$ (94,595 square miles) giving a population density of 0.16 people per kilometre. The majority (81\%) of Indigenous Australians and a minor proportion of non-Indigenous Australians live in remote and regional communities. ${ }^{32,33}$

\section{Institution Where Work Was Performed} Department of Respiratory and Sleep Medicine, Royal Darwin Hospital, Darwin, Northern Territory, Australia and Darwin Respiratory and Sleep Health, Darwin Private Hospital, Darwin, Northern Territory, Australia. 0810.

\section{Development of the "Top End Sleepiness Scale” (TESS) Questionnaire}

A focus group from the Top End NT region was formed in the development of the TESS questionnaire. The focus group consisted of eleven individuals, including Indigenous representatives (Traditional Indigenous custodians), Anthropologist, Sleep Physician, remote clinical nurse consulatants and Flinders university academics with in-depth knowledge in Indigenous Australians health issues. Indigenous Australian-specific public health resources and clinical literature materials were provided to the focus group for review prior to the development of the TESS questionnaire.

A nominal group technique ${ }^{34}$ was undertaken to identify possible specific unsuitable questionnaire items within the ESS and to identify alternative culturally relevant daily activities that would likely induce the onset of sleep to a similar degree. The nominal group process concluded that the current ESS tool is unsuitable for the Indigenous Australian people living in the regional and remote communities and suggested alternative questions, simplification of language and addition of pictorial representations for each questionnaire item. The group also suggested for the pictorial representation to be generic and not to represent any specific Indigenous Australian populations appearance, as such various Indigenous Australian people by ethnic descent can vary in their appearance and corpulence or stature. Thus, these (pictorials) were represented as cartoons so that this could be adopted across wider Indigenous Australian population. Several meetings were held over a nine-month period, with each meeting lasting over one to three hours before arriving at the final approved version by the group.

\section{The "Top End Sleepiness Scale" (TESS) Questionnaire}

After several reviews and alterations of the art work (drawn by author TS), the focus group approved the (TESS) sleepiness assessment tool be tested (piloted) among the NT Indigenous Australian people. The TESS questionnaire consisted of items representing daily realistic activities/scenarios that would induce sleepiness to similar degree (ESS) for Indigenous people living in the regional and remote regions of the NT of Australia: 1. Siting and fishing, waiting for the fish to bite; 2. Sitting with one other person talking to you; 3 . Riding in a car or bus for some time; 4. Sitting in a group listening to other people talk or tell stories; 5. Waiting for your turn at the medical clinic; 6. Watching television (TV). Patients were asked to score themselves on a subjective four point scale rating the chance of them falling asleep in the situation; never (score of 0 ), sometimes (score of 1), most times (score of 2) or always (score of 3). The final proposed tool that was approved by the group for trial in this study is illustrated in Figure 1.

\section{Study Participants}

Participants were recruited for this study between 2017 and 2020. Included were only adult Indigenous Australian patients aged 18 years and above, undergoing a diagnostic PSG from the TEHS region, willing and able to give informed consent for the study. Patients were recommended to undergo a diagnostic PSG as per the discretion of treating Respiratory and Sleep specialist following an initial clinical consultation. The patients were referred to the specialist sleep service by primary health physicians, general practitioners and specialist practitioners for assessment of clinically suspected OSA.

\section{Questionnaire Administration}

Prior to undergoing a diagnostic PSG, all study participants were asked to complete TESS and ESS questionnaires. The questionnaires were administered by the sleep technologists who were briefed/trained by the research team on the research project. Indigenous language interpreters were not used to assist in administration of the questionnaires where participants did not speak English as a first language, in order to reflect the intended use of the tool in a primary health care level. Clinical and demographic characteristics were recorded including: age, sex, height, weight, body mass index (BMI) and medical comorbid conditions; such as the presence of diabetes, hypertension and heart disease. Further, alcohol and smoking history were also recorded. 


\begin{tabular}{|l|l|}
\hline \multicolumn{1}{|c|}{ Information - How to use TESS } & \multicolumn{1}{c|}{ Information for the Patient } \\
\hline $\begin{array}{l}\text { It is essential that you guide the patient through } \\
\text { the questionnaire and DO NOT hand the } \\
\text { questionnaire to the patient to be filled out and } \\
\text { returned. }\end{array}$ & $\begin{array}{l}\text { This is a quick test for measuring the likeliness of } \\
\text { you falling asleep during the day. }\end{array}$ \\
$\begin{array}{l}\text { - All questions must be completed. } \\
\text { - It is not essential that the patient has recently } \\
\text { undertaken all the described activities in order to } \\
\text { provide a response. The patient need only be able } \\
\text { to imagine undertaking the activity and provide } \\
\text { the likelihood that they think they would fall } \\
\text { asleep. }\end{array}$ & $\begin{array}{l}\text { Please imagine you are in the situations below and } \\
\text { tell us whether you think you would fall asleep. } \\
\text { feel tired, but whether you would actually doze } \\
\text { off. Please circle an option after each situation } \\
\text { below: }\end{array}$ \\
\hline
\end{tabular}

Question 1) If you were: Sitting and fishing, waiting for the fish to bite.

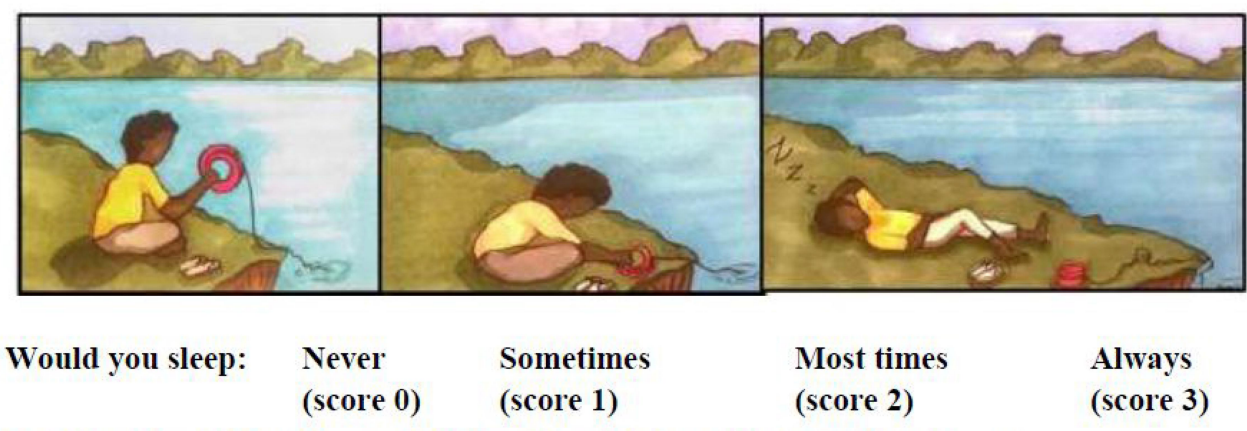

Question 2) If you were: Sitting with one other person talking to you.

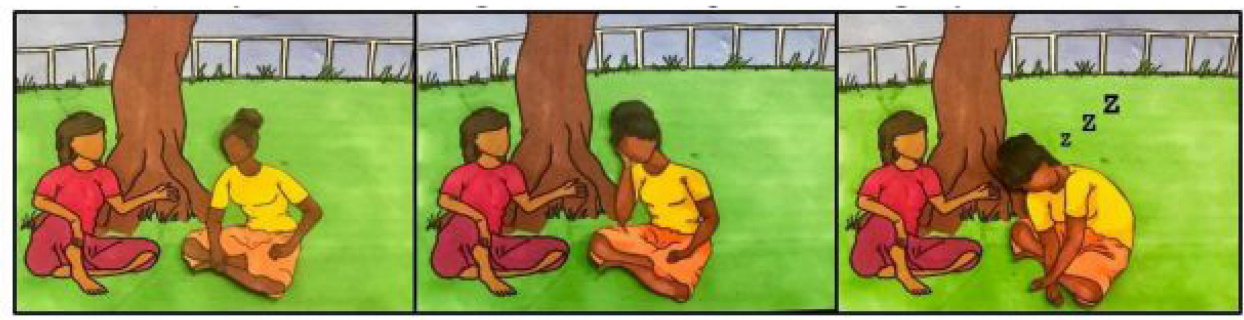
Would you sleep:
Never
Sometimes
Most times
Always
(score 0)
(score 1)
(score 2)
(score 3)

Question 3) If you were: Riding in a car or bush bus for some time.

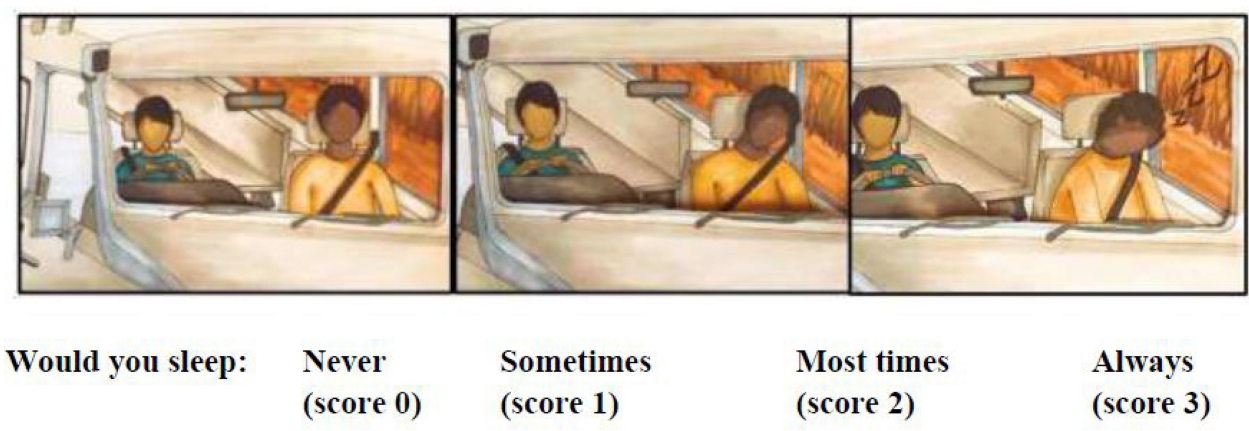

Figure I (Continue). 
Question 4) If you were: Sitting in a group listening to other people talk or tell stories.

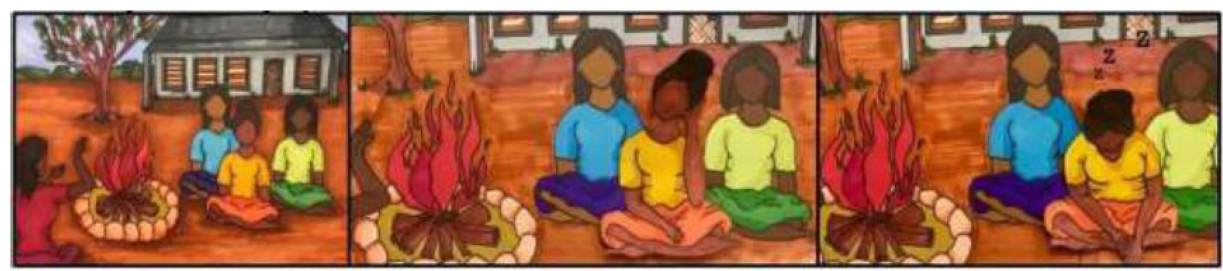

$\begin{array}{lllll}\text { Would you sleep: } & \begin{array}{l}\text { Never } \\ \text { (score 0) }\end{array} & \begin{array}{l}\text { Sometimes } \\ \text { (score 1) }\end{array} & \begin{array}{l}\text { Most times } \\ \text { (score 2) }\end{array} & \begin{array}{l}\text { Always } \\ \text { (score 3) }\end{array}\end{array}$

Question 5) If you were: Waiting for your turn at the clinic.

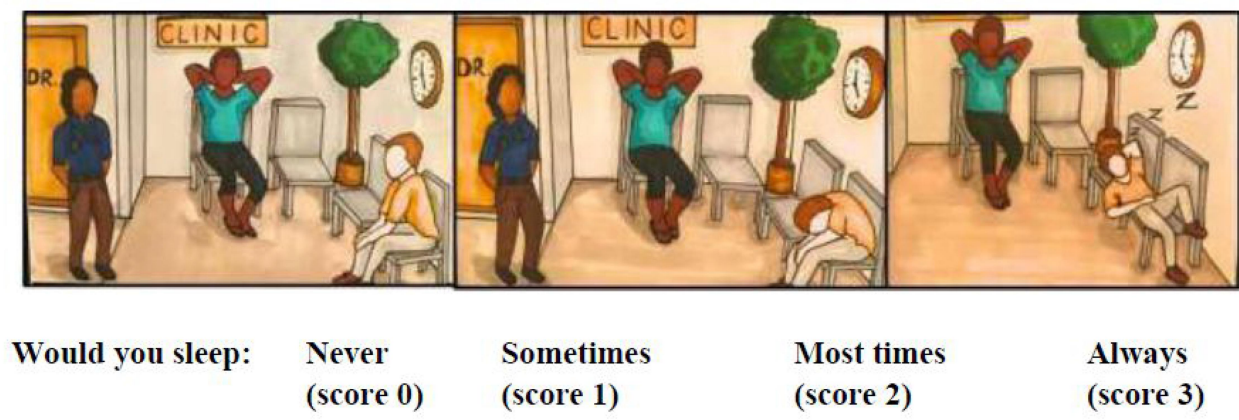

Question 6) If you were: Watching TV

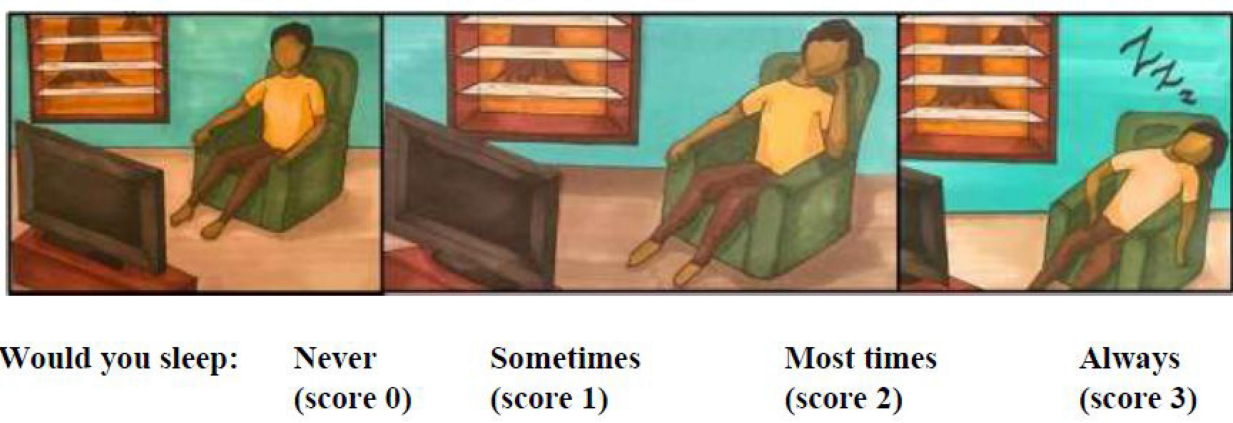

Please add up the total score of all the circled responses.

\section{TESS SCORE:}

ARTWORK REMAINS THE PROPERTY OF TEAGAN SHORT ALL RIGHTS RESERVED, 2017

Electronic version available for use at: www.darwinsleephealth.com.au

Figure I Top End Sleepiness Scale.

\section{Polysomnography (PSG) Data}

All PSGs were performed at the Darwin-based sleep service (DRSH) facility accredited by the National Association of Testing Authorities, Australia (NATA) and the Australian Sleep Association (ASA). Sleep studies were performed and analysed in accordance with the American Academy of Sleep Medicine recommendations and as described in a recent publication from this centre. $^{20-22}$ Polysomnography data was extracted to include information on the severity of sleep disordered 
breathing using Apnoea-Hypopnoea Index (AHI) criteria: AHI $<5$ (normal range), AHI $\geq 5$ and $<15$ (mild sleep apnoea), AHI $\geq 15$ and $<30$ (moderate sleep apnoea), AHI $\geq 30$ (Severe sleep apnoea).

\section{Statistical Methods}

Continuous parameters were tested for normality with the Shapiro Wilks distribution test. Age appeared normally distributed while body mass index (weight/height ${ }^{2}$ ), AHI, ESS and TESS score were found to deviate from normality to a significant extent and thus were treated as nonparametric. Non-parametric parameters were presented as medians (interquartile ranges (IQRs)), normally distributed parameters as means (95\% confidence intervals (CIs)), and categorical parameters as numbers (\%). Total TESS scores were also presented with means ( $95 \%$ CI's). Median TESS scores were compared between sex, age categories (age in years $18<35,35<45,45<55$ and $\geq 55$ ), BMI categories (BMI $<25,25<30,30<35$ and $\geq 35$ ) and presence of chronic disease utilising equality of medians test.

Split half reliability of the TESS was tested by correlating the sum of scores for odd questions with those of even questions using Spearman correlation coefficient, and an equality of medians test. Cronbach's $\alpha$ was used to assess internal consistency and given for the scale as a whole and on deletion of each individual question. An $\alpha$ greater than 0.7 was considered sufficient for consistency. Consistency was further assessed with Spearman correlation coefficient between individual questions and rated as poor $(0-0.3)$, fair $(0.3-0.5)$, moderate $(0.5-0.7)$ or strong $(>0.7)$. Sensitivity, specificity, positive predictive power and negative predictive power for abnormal scores of TESS on OSA outcome and OSA severity were calculated in the normal fashion and stratified by sex. All data were analysed in STATA IC 15 (StataCorp, Texas) and alpha was set to 0.05 throughout.

\section{Ethical Consideration}

This study was approved by the Human Research Ethics Committee of the NT Department of Health/TEHS and Menzies School of Health Research. (Reference No: HREC 2017-2831). All included study participants in this study provided informed consent to participate in this study and the study was conducted in accordance with the Declaration of Helsinki. Permission to use the Epworth Sleepiness Scale for this study has been granted by respective authorities.

\section{Results}

A total of 82 Indigenous Australian patients were included in this study. Three patients declined participation. Half (50\%) were male, with a mean age of 45 years $(95 \%$ CI $42.9,48.05)$ and the majority were obese $(78 \%, \mathrm{n}=63)$, with a median BMI 33.6 (IQR 30.86, 38.95) (Table 1). The majority of the study participants were recorded to have

Table I Demographic and Clinical Parameters of the Study Participants

\begin{tabular}{|c|c|}
\hline Clinical Parameters & $\begin{array}{l}\text { Participants } \\
\qquad(\mathbf{n}=\mathbf{8 2})\end{array}$ \\
\hline Age (mean, $95 \% \mathrm{Cl}$ ) & $45.47(42.9,48.05)$ \\
\hline $18<35$ & 17 (2।\%) \\
\hline $35<45$ & $24(29 \%)$ \\
\hline $45<55$ & $24(29 \%)$ \\
\hline$\geq 55$ & $17(2 \mid \%)$ \\
\hline Males & $4 \mid(50 \%)$ \\
\hline BMI (Median, IQR) $(n=8 I)$ & $33.67(30.86,38.95)$ \\
\hline Normal Weight $(B M I<25)$ & $2(3 \%)$ \\
\hline Overweight (BMI $25<30$ ) & $16(20 \%)$ \\
\hline Obese (BMI $30<35)$ & $25(31 \%)$ \\
\hline Morbidly obese $(B M I \geq 35)$ & $38(47 \%)$ \\
\hline $\begin{array}{l}\text { Consumed alcohol on study date } \\
(n=79)\end{array}$ & I (I\%) \\
\hline Medical co-morbidities & $59(72 \%)$ \\
\hline Hypertension $(n=80)$ & 31 (39\%) \\
\hline Diabetes $(n=8 I)$ & $28(35 \%)$ \\
\hline Heart disease $(n=60)$ & II (I8\%) \\
\hline Completed TESS & $82(97 \%)$ \\
\hline ESS (median (IQR)) & $8(5,12)$ \\
\hline TESS (median (IQR)) & $5(3,7)$ \\
\hline Total AHI $(n=80)$ & $30.9(12.8,55.45)$ \\
\hline OSA $(A H I \geq 5)(n=80)$ & $72(90 \%)$ \\
\hline Mild $($ AHI $5<$ I5) & $16(22 \%)$ \\
\hline Moderate $(\mathrm{AHI}$ I5 $<30)$ & $15(2 \mid \%)$ \\
\hline Severe $(A H I \geq 30)$ & $4 \mid(57 \%)$ \\
\hline
\end{tabular}

Abbreviations: $\mathrm{Cl}$, confidence interval; $\mathrm{BMI}$, body mass index; IQR, interquartile range; TESS, Top End Sleepiness Scale; ESS, Epworth Sleepiness Scale; AHI, apneahypopnea index; OSA, obstructive sleep apnea. 
some form of chronic medical co-morbidities $(72 \%, \mathrm{n}=59)$. According to the AHI criteria (AHI $>5 /$ hour), OSA was present in the majority of the study participants $(90 \%, \mathrm{n}=72)$ with most of them noted to have severe OSA $(57 \%, n=41)$.

The TESS total score was non-parametrically distributed (Shapiro-Wilk W=0.938, $\mathrm{p}<0.001$ ) and skewed towards zero (Figure 2). Median TESS score was 5 (IQR $3,7)$, and when stratified by demographic parameters did not significantly differ (age category $\mathrm{p}=0.224$, sex $\mathrm{p}=0.657$, BMI category $\mathrm{p}=0.188$, chronic disease $\mathrm{p}=0.912)$ (Table 2).

Individual TESS question data was available for 65 (78\%) patients. All patients answered each of the six questions, bar one patient who answered five (Table 3). Median scores for each individual question did not significantly differ, nor did split half scores $(2(1,4)$ vs $3(1,4)$ $\mathrm{p}=0.790)$ which recorded a Spearman correlation coefficient of 0.71 . Cronbach's $\alpha$ was 0.81 and ranged from 0.75 to 0.80 on stepwise deletion of questions.

Overall, correlation between scores on individual questions was fair (average Spearman's coefficient 0.39) (Table 4). The lowest values were recorded for question one (typically poor $(0.2-0.3)$ to fair $(0.3-0.4)$ ), and the highest for question three (typically fair $(0.4-0.5)$ ). The correlation to the total TESS score was fair for question one $(0.5-0.6)$, and moderate $(0.6-0.7)$ to strong $(0.7-0.8)$ for each other question.
Univariate linear regression between ESS \& total AHI did not show a significant correlation, while TESS \& total AHI did show a significant correlation, though the fit was poor $(p=0.072, R 2=0.032$ and $p=0.049, R 2=0.037$ for ESS and TESS, respectively) (Figure 3). Comparison of area under the curve statistic showed the TESS to consistently perform better in the prediction for the presence of moderate to severe OSA (AHI $\geq 15$ ) compared to the ESS. For the TESS instrument assessed overall, the AUC (AUC $=0.630,95 \%$ CI $0.489,0.771$ ) was greater than that for the ESS (AUC $=0.55395 \%$ CI $0.409,0.697$ ), though the difference was not significant $(\mathrm{p}=0.149)$ (Figure 4A). The greatest AUCs were noted at TESS cut-off points of " 3 " and " 8 ". When utilising cut-offs of $\geq 3$ or $\geq 8$ for the TESS and $\geq 8$ for the ESS, the performance of TESS remained superior $(\geq 3 \mathrm{AUC}=0.607,95 \%$ CI $0.497,0.717$ and $\geq 8$ AUC $=0.619,95 \%$ CI $0.535,0.703$ vs ESS $\geq 8$ $\mathrm{AUC}=0.501,95 \%$ CI $0.372,0.630)$ and trended towards significance $(\mathrm{p}=0.177$ and $\mathrm{p}=0.072$ for TESS $\geq 8$ and TESS $\geq 3$, respectively) (Figure 4B).

Sensitivity and specificity of TESS were tested using cut-offs of TESS $\geq 3$ and TESS $\geq 8$ (Table 5). The lower cut-off score showed significantly greater sensitivity than the higher cut-off score ( $84 \%$ and $32 \%$ respectively), and this was reversed for specificity (38\% vs $92 \%)$. Positive predictive values were comparable for both cut-offs ( $76 \%$ and $90 \%$, respectively) and when predicting severity of

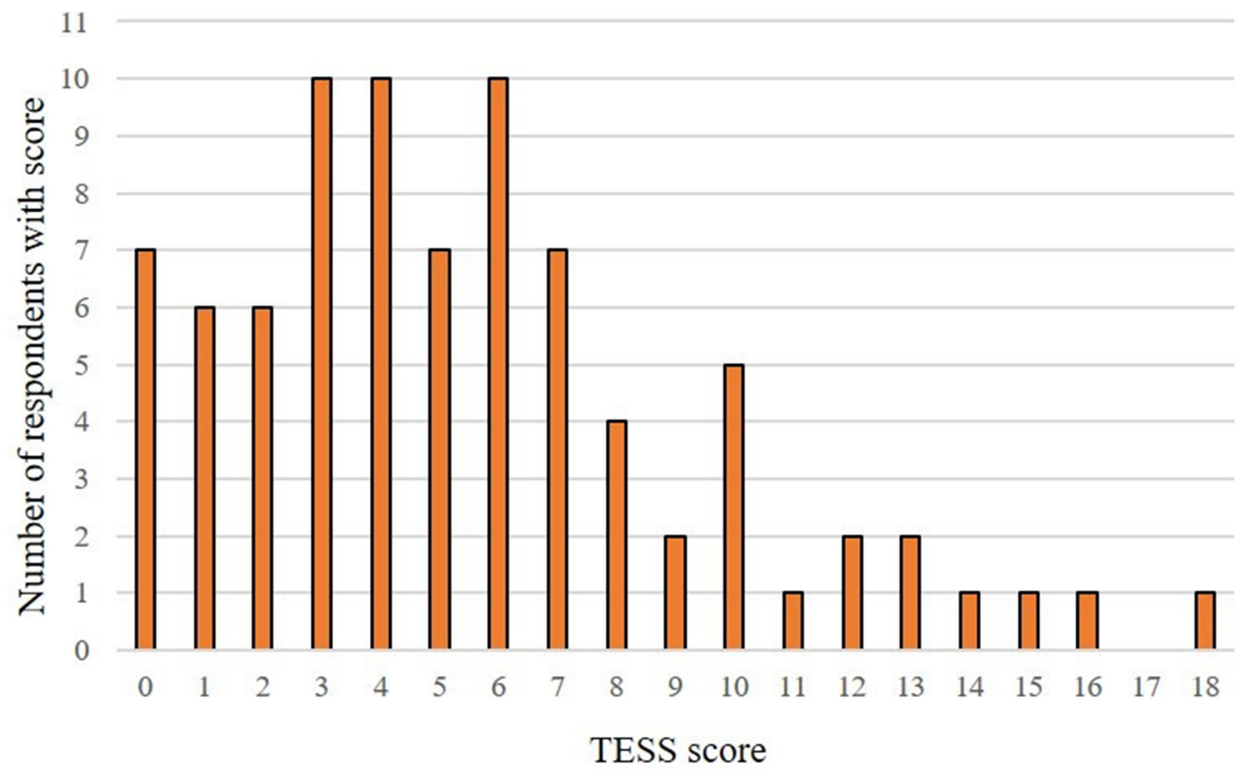

Figure 2 Frequency plot of Top End Sleepiness Scale scores. Abbreviation: TESS, Top End Sleepiness Scale. 
Table 2 Median and Mean Top End Sleepiness Scale Scores by Demographic Breakdown

\begin{tabular}{|c|c|c|c|}
\hline Clinical Parameters & TESS Median (IQR)* & TESS Mean $(95 \% \mathrm{Cl})^{*}$ & Patients with OSA (n (\%)) \\
\hline \multicolumn{4}{|l|}{ Age } \\
\hline $18-35(n=16)$ & $5.5(3.5,10)$ & $7.06(4.35,9.78)$ & 14 (88\%) \\
\hline $35-45(n=24)$ & $4.5(1.5,6)$ & $4.21(2.97,5.45)$ & $22(92 \%)$ \\
\hline $45-55(n=23)$ & $6(3,10)$ & $6.83(5.22,8.44)$ & 21 (9l\%) \\
\hline $55+(n=17)$ & $3(2,6)$ & $4.4 \mathrm{I}(2.39,6.44)$ & $15(88 \%)$ \\
\hline \multicolumn{4}{|l|}{ Sex } \\
\hline Female $(n=4 I)$ & $5(3,7)$ & $5.29(4.11,6.47)$ & $35(85 \%)$ \\
\hline Male $(n=39)$ & $5(3,9)$ & $5.87(4.47,7.28)$ & $37(95 \%)$ \\
\hline \multicolumn{4}{|l|}{ BMI } \\
\hline Normal weight $(n=2)$ & 7,12 & 9.5 & $2(100 \%)$ \\
\hline Overweight $(n=15)$ & $4(2,6)$ & $4.73(2.8,6.67)$ & $12(80 \%)$ \\
\hline Obese $(n=25)$ & $5(3,7)$ & $5.52(3.71,7.34)$ & $20(80 \%)$ \\
\hline Obese II $(n=37)$ & $6(3,8)$ & $5.9(4.58,7.20)$ & $37(100 \%)$ \\
\hline \multicolumn{4}{|l|}{ Chronic disease } \\
\hline No $(n=26)$ & $5(3,7)$ & $5.73(4.28,7.18)$ & $24(92 \%)$ \\
\hline Yes $(n=54)$ & $5(2,8)$ & $5.5(4.34,6.66)$ & $48(89 \%)$ \\
\hline
\end{tabular}

Note: *Median and mean scores calculated only for patients with AHI data.

Abbreviations: TESS, Top End Sleepiness Scale; IQR, interquartile range; Cl, confidence interval; OSA, obstructive sleep apnea; BMI, body mass index.

Table 3 Breakdown of Scores for Individual Top End Sleepiness Scale Questions with Cronbach's $\alpha$ and Split Half Reliability Value

\begin{tabular}{|c|c|c|c|c|}
\hline $\begin{array}{l}\text { Question } \\
\text { Number }\end{array}$ & Median (IQR) & Mean $(95 \% \mathrm{Cl})$ & Cronbach's $\alpha$ & Spearman Correlation \\
\hline TESS-I $(n=64)$ & $0(0,1)$ & $0.55(0.35,0.74)$ & 0.80 & \\
\hline TESS-2 $(n=65)$ & $0(0,1)$ & $0.58(0.37,0.8)$ & 0.76 & \\
\hline TESS-3 $(n=65)$ & $I(0,2)$ & $1.4(1.12,1.68)$ & 0.79 & \\
\hline TESS-4 $(n=65)$ & $0(0,1)$ & $0.78(0.54,1.03)$ & 0.75 & \\
\hline TESS-5 $(n=65)$ & $I(0, I)$ & $0.89(0.63,1.16)$ & 0.78 & \\
\hline TESS-6 $(n=65)$ & $I(I, 3)$ & $1.55(1.28,1.82)$ & 0.77 & \\
\hline TESS Total $(n=83)$ & $5(3,7)$ & $5.49(4.62,6.37)$ & 0.81 & \\
\hline Odd Half $(n=64)$ & $2(I, 4)$ & $2.86(2.3 \mathrm{I}, 3.4 \mathrm{I})$ & & \multirow[t]{2}{*}{0.71} \\
\hline Even half $(n=65)$ & $3(I, 4)$ & $2.92(2.34,3.5 \mathrm{I})$ & & \\
\hline
\end{tabular}

Abbreviations: TESS, Top End Sleepiness Scale; IQR, interquartile range.

OSA, though the negative predictive value was higher for the lower cut-off score (50\% vs $37 \%)$. Sensitivity, specificity and positive predictive power were greater among males for both cut-off scores, however, the difference in sensitivity was minor.
Sensitivity and specificity of the TESS tool were comparable to other common questionnaires currently used in clinical practice in the prediction of presence of moderate to severe OSA (Table 6). Positive predictive value changed when a cut-off value of TESS $\geq 8$ was used instead of 
Table 4 Spearman Correlation Coefficient Between Questions Within Top End Sleepiness Scale and Top End Sleepiness Scale Total Score

\begin{tabular}{|l|c|c|c|c|c|c|c|}
\hline Questions & TESS-I & TESS-2 & TESS-3 & TESS-4 & TESS-5 & TESS-6 & TESS Total \\
\hline TESS-I & & 0.40 & 0.26 & 0.26 & 0.23 & 0.38 & 0.54 \\
\hline TESS-2 & 0.001 & & 0.41 & 0.48 & 0.42 & 0.33 & 0.66 \\
\hline TESS-3 & 0.040 & 0.001 & & 0.49 & 0.40 & 0.42 & 0.74 \\
\hline TESS-4 & 0.036 & $<0.001$ & $<0.001$ & & 0.48 & 0.40 & 0.71 \\
\hline TESS-5 & 0.066 & 0.001 & 0.001 & $<0.001$ & & 0.47 & 0.71 \\
\hline TESS-6 & 0.002 & 0.007 & 0.001 & 0.001 & $<0.001$ & $<$ \\
\hline TESS Total & $<0.001$ & $<0.001$ & $<0.001$ & $<0.001$ & $<0.001$ & $<0.001$ \\
\hline
\end{tabular}

Note: Right upper half reports Spearman correlation coefficient, while left lower half reports the respective p-values of the coefficient.

Abbreviation: TESS, Top End Sleepiness Scale.

TESS $\geq 3$ (90\% and $76 \%$, respectively), sensitivity fell and specificity increased.

\section{Discussion}

To the best of our knowledge, this is the first study to evaluate a culturally and clinically relevant sleepiness assessment tool for use in the clinical assessment of OSA among Indigenous Australian people. Our study demonstrates that the proposed TESS scoring scale to assess daytime sleepiness correlates reasonably in predicting the presence of OSA in comparison to the other currently available sleep assessment tools among Indigenous Australian people.

In the Australian perspective, literature evidence suggests that OSA is highly prevalent in the non-Indigenous population. ${ }^{35,36}$ However, more recently published reports show that sleep health issues could be equally prevalent among Indigenous Australian people. ${ }^{18-24,37}$ Moreover, a higher proportion of chronic health conditions ${ }^{9,11,13}$ and obesity $^{38,39}$ are frequently observed among the Indigenous Australian population, and obesity is considered to be one of the main risk factors for OSA. ${ }^{40}$ Hence, it may be reasonable to presume that in the absence of a culturally appropriate sleepiness screening tool, OSA among Indigenous people is likely to be under or undiagnosed, and thus not be treated, which may in turn potentially contribute to heightened adverse health consequences. Therefore, we believe our proposed TESS scale may be of value in screening high-risk Indigenous patients in recommending appropriate investigations, such as to undergo a diagnostic PSG to confirm the presence of OSA.

It is estimated that there are approximately 370 million people of Indigenous origin worldwide living in over 90 countries and making up $5 \%$ of the global population. ${ }^{41,42}$
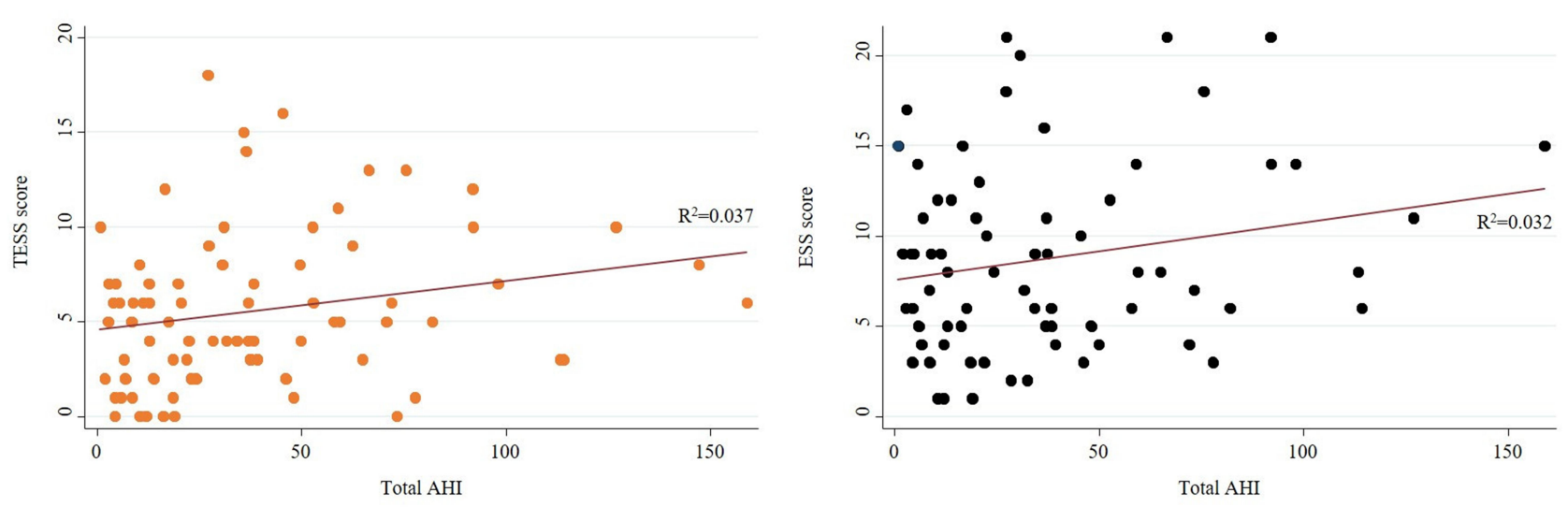

Figure 3 Scatterplots showing the relationship between TESS (left) and ESS (right) scores and total AHI. Abbreviations: TESS, Top End Sleepiness Scale; ESS, Epworth Sleepiness Scale; AHI, apnea-hypopnea index. 

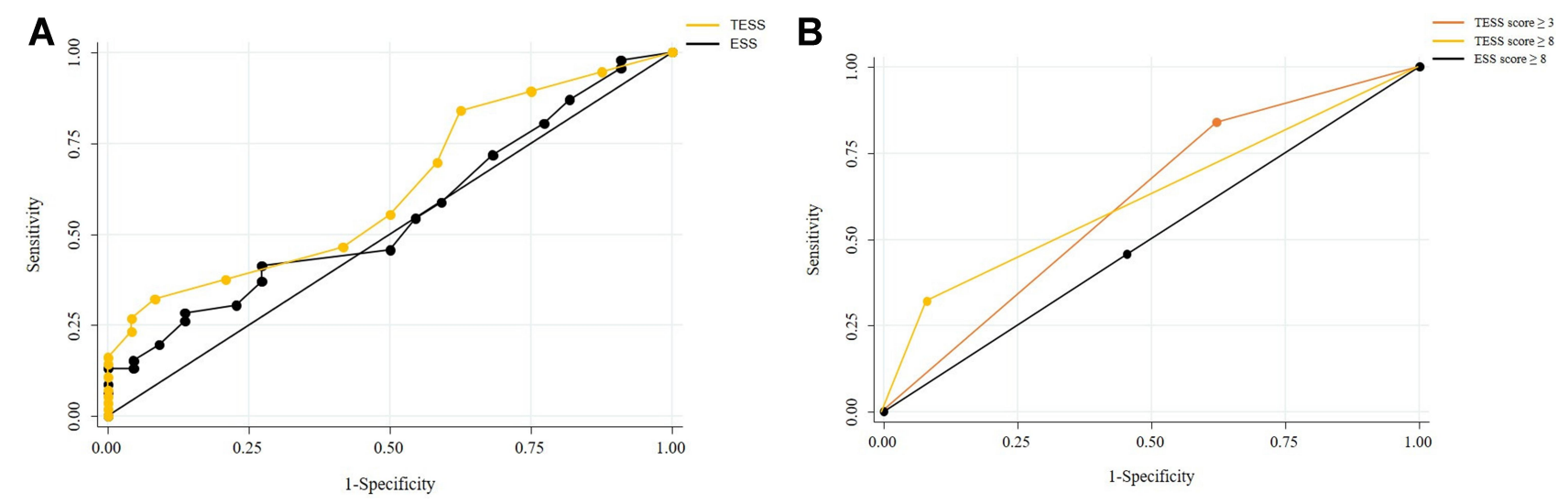

Figure 4 Area under the curve (AUC) receiver operator characteristic (ROC) for TESS and ESS tools sensitivity and I-specificity overall (A) and for cut-offs TESS $\geq 3$, TESS $\geq 8$ and ESS $\geq 8$ (B).

Abbreviations: TESS, Top End Sleepiness Scale; ESS, Epworth Sleepiness scale.

Indigenous people are noted to have poorer health status and its outcomes, and also face other unfavourable social determinants of health and geographic isolation. ${ }^{9-13,43-46}$ The absence of culturally appropriate screening tools for the diagnosis and management of chronic health conditions, including OSA, may lead to higher morbidity and mortality and further increase the health care costs and expenditure in these populations. ${ }^{47}$
In the recent past, sleep health issue have been increasingly acknowledged to be a major contributor to the chronic health burden among Indigenous populations, especially in the English speaking OECD countries. ${ }^{18-24,37,48-54}$ Currently, in the Australian context, the ESS, ${ }^{25}$ Berlin Questionnaire, ${ }^{55}$ OSA 50, and STOPBang $^{56-58}$ are the main screening tools recommend in the assessment or screening of patients prior to undergoing or

Table 5 Sensitivity, Specificity, Positive and Negative Predictive Values of Top End Sleepiness Scale in the Prediction of Obstructive Sleep Apnea $(\mathrm{AHI} \geq 15)$, Severity, and by Sex Stratification

\begin{tabular}{|c|c|c|c|c|}
\hline Parameters & Sensitivity & Specificity & Positive Predictive Value & Negative Predictive Value \\
\hline \multicolumn{5}{|c|}{ TESS $\geq 3$} \\
\hline$A H I \geq I 5$ & 84 & 38 & 76 & 50 \\
\hline Moderate OSA & 67 & 18 & 18 & 67 \\
\hline Severe OSA & 90 & 36 & 65 & 73 \\
\hline \multicolumn{5}{|c|}{ Sex } \\
\hline Male & 85 & 50 & 90 & 38 \\
\hline Female & 83 & 33 & 61 & 60 \\
\hline \multicolumn{5}{|c|}{ TESS $\geq 8$} \\
\hline $\mathbf{A H I} \geq \mathbf{I} 5$ & 32 & 92 & 90 & 37 \\
\hline Moderate OSA & 20 & 72 & 16 & 77 \\
\hline Severe OSA & 37 & 87 & 79 & 51 \\
\hline \multicolumn{5}{|c|}{ Sex } \\
\hline Male & 33 & 100 & 100 & 21 \\
\hline Female & 30 & 89 & 78 & 50 \\
\hline
\end{tabular}

Abbreviations: OSA, obstructive sleep apnea; TESS, Top End Sleepiness Scale. 
Table 6 Sensitivity, Specificity, Positive and Negative Predictive Values of Top End Sleepiness Scale in the Prediction of Moderate to Severe Obstructive Sleep Apnea for Scores $\geq 3$ and $\geq 8$ Compared to Other Alternative Obstructive Sleep Apnea Specific Screening Questionnaires

\begin{tabular}{|l|c|c|c|c|c|c|}
\hline Items & $\begin{array}{c}\text { Berlin } \\
\text { Questionnaire }\end{array}$ & $\begin{array}{c}\text { STOP-BANG Cut-Off } \\
\mathbf{2}\end{array}$ & $\begin{array}{c}\text { STOP-BANG } \\
\mathbf{2 4}\end{array}$ & $\begin{array}{c}\text { OSA } \\
\mathbf{5 0}\end{array}$ & $\begin{array}{c}\text { TESS Cut-Off } \\
\mathbf{3}\end{array}$ & $\begin{array}{c}\text { TESS Cut-Off } \\
\mathbf{3}\end{array}$ \\
\hline Sensitivity & 82 & 94 & 81 & 94 & 84 & 32 \\
\hline Specificity & 39 & 32 & 51 & 31 & 38 & 92 \\
\hline PPV & & & & & 76 & 9 \\
\hline NPV & & & & & 50 & 37 \\
\hline
\end{tabular}

Abbreviations: OSA, obstructive sleep apnea; TESS, Top End Sleepiness Scale; PPV, positive predictive value; NPV, negative predictive value.

qualifying for a diagnostic sleep study to confirm the presence of OSA, in particular, directly through primary health care setting. Moreover, several studies have reported that ESS may lack accuracy in predicting OSA severity, ${ }^{59-61}$ including patients with hypertension. ${ }^{62}$ However, some of the aforementioned assessment tools may not be applicable, appropriate or relevant to Indigenous Australian people. Moreover, a recent study $\operatorname{assessing}^{58}$ the three screening questionnaires plus ESS at primary health care level in clinical decision-making for patients directly to undergo a diagnostic sleep study concluded that the STOP-Bang, Berlin Questionnaire, and OSA-50 questionnaires are useful only to rule in, but not to rule out presence of OSA. In a similar vein as demonstrated in this study, our proposed TESS tool is not inferior to the currently available screening questionnaires to rule in for the presence of OSA among an Indigenous cohort.

The sensitivity and specificity of the TESS demonstrated that a cut-off of $\geq 3$ had greater sensitivity, while $\geq 8$ had lower sensitivity, but much higher specificity. Although typically for a screening tool, it may be more meaningful to use higher sensitivity compared to higher specificity. In the authors opinion, in this context a lower sensitivity/higher specificity tool may be of greater benefit. Using a cut-off score of $\geq 3$ with higher sensitivity may result in more tests being ordered for Indigenous people in this resource poor setting, many of which may yield negative results. Therefore, it may be reasonable to use a TESS cut-off score of $\geq 8$ with a higher specificity in recommending or considering patients to undergo a diagnostic sleep study.

Using culturally and clinically relevant tools, adapted specifically to Indigenous Australian people such as the TESS tool proposed in this study may complement the holistic management of sleep disorders in this population.
Furthermore, the TESS concept could be adapted and modified according to other ethnic Indigenous populations globally. Although our proposed TESS tool appears to be useful among the smaller sample Indigenous Australian population we tested in this study, however, the true strengths of the TESS tool will only be apparent when the TESS tool be used widely among wider Indigenous population in the primary health care level. Hence, further studies are however warranted to test the validity and acceptability of this proposed TESS tool.

\section{Limitations of the Study}

We acknowledge the number of study participants was small in our study, however, it is not surprising given the logistical, cultural and financial barriers to accessing sleep studies in this target study Indigenous Australian population. Many patients are flown to capital Darwin from remote communities which, in some circumstances are only accessible seasonally by light aircraft. The nature of the study design resulted in a high prevalence of OSA in the study group due to high pre-test clinical suspicion of OSA. The ESS was validated using multiple sleep latency test (MSLT) as an objective measure of subjective daytime sleepiness. It would have been useful in our study to validate the proposed TESS with MSLT data. However, carrying out MSLT testing purely for the purpose of such research will result in unprecedented challenges due to ethical, cultural, logistic and financial barriers, so AHI was used as the primary outcome in our study. Furthermore, during initial designing of our study we did not record Berlin questionnaire, OSA 50, of STOP-Bang in our study participants. In hindsight, we believe this information would have been very valuable and would have further strengthened our study outcome. Nevertheless, there is room for further research in 
validating/comparing TESS with other sleep assessment tools.

\section{Conclusion}

The TESS subjective daytime sleepiness assessment tool correlates with OSA in Top End NT Indigenous Australian patients when judged against AHI. Furthermore, the TESS tool showed sensitivity and specificity similar to that of the Berlin Questionnaire, STOP-Bang, OSA 50 and ESS. As such, utilising the TESS tool with a cut-off score $\geq 8$ may complement other currently available screening tools, which may offer greater utility in informed referral for further assessment and management of sleep disorders among Indigenous Australian people.

\section{Abbreviations}

AHI, Apnea-Hypopnea Index; ASA, Australia and the Australian Sleep Association; AUC, Area under the curve; BMI, Body mass index; CI, Confidence interval; DPH, Darwin Private Hospital; DRSH, Darwin Respiratory and Sleep health; ESS, Epworth Sleepiness Scale; HREC, Human Research Ethics Committee; IQRs, Interquartile ranges; MSLT, Multiple sleep latency test; NATA, National Association of Testing Authorities; NT, Northern Territory; NPV, Negative predictive value; OECD, Organisation for Economic Co-operation and Development countries; OSA, Obstructive sleep apnea; PPV, Positive predictive value; PSG, Polysomnography; RDH, Royal Darwin Hospital; TESS, The Top End Sleepiness Scale; TEHS, Top End Health Service; TV, Television.

\section{Acknowledgment}

We thank all who had input into the nominative focus group process in developing the TESS. Special thanks to Geoffrey Angeles, Don Christophersen, Karen Piper and Penelope Johnson for their contribution. We thank all staff at Darwin Respiratory and Sleep Health, with special acknowledgment to the sleep technologists Rochelle Calderon, and Charmin Atos for their support during this study. Thanks to statistician Anh-Minh Nguyen for her contribution. Furthermore, we are grateful for the community Aboriginal health care workers and Royal Darwin Hospital Respiratory Clinical Nurse Consultants in co-ordinating sleep studies for patients from remote communities. We also extend our sincere appreciation to our Indigenous health worker (Australian Indigenous Luritja descendent) Mr Izaak Thomas from our respiratory and sleep chronic disease co-ordination unit at the, Royal Darwin Hospital, in reviewing and approving this manuscript for the appropriateness of the representation and respect of the Indigenous context represented in this study.

\section{Author Contributions}

All authors made substantial contributions to conception and design, acquisition of data, or analysis and interpretation of data; took part in drafting the article or revising it critically for important intellectual content; agreed to submit to the current journal; gave final approval of the version to be published; and agree to be accountable for all aspects of the work.

\section{Funding}

There is no funding to report.

\section{Disclosure}

All authors declare no conflicts of interest for this work.

\section{References}

1. Benjafield AV, Ayas NT, Eastwood PR, et al. Estimation of the global prevalence and burden of obstructive sleep apnoea: a literature-based analysis. Lancet Respir Med. 2019;7(8):687-698. doi:10.1016/ S2213-2600(19)30198-5

2. Senaratna CV, Perret JL, Lodge CJ, et al. Prevalence of obstructive sleep apnea in the general population: a systematic review. Sleep Med Rev. 2017;34:70-81. doi:10.1016/j.smrv.2016.07.002.

3. Punjabi NM, Shahar E, Redline S, et al. Sleep-disordered breathing, glucose intolerance, and insulin resistance: the Sleep Heart Health Study. Am J Epidemiol. 2004;160(6):521-530. doi:10.1093/aje/ kwh261

4. Kasai T, Floras JS, Bradley TD. Sleep apnea and cardiovascular disease: a bidirectional relationship. Circulation. 2012;126 (12):1495-1510. doi:10.1161/CIRCULATIONAHA.111.070813

5. Marshall NS, Wong KKH, Liu PY, et al. Sleep apnea as an independent risk factor for all-cause mortality: the Busselton Health Study. SLEEP. 2008;31(8):1079-1086.

6. Peppard PE, Young T, Palta M, et al. Prospective study of the association between sleep-disordered breathing and hypertension. $N$ Engl J Med. 2000;342(19):1378-1384. doi:10.1056/NEJM20000 5113421901

7. Jean-Louis G, Zizi F, Clark LT, et al. Obstructive sleep apnea and cardiovascular disease: role of the metabolic syndrome and its components. J Clin Sleep Med. 2008;4(3):261-272. doi:10.5664/ jesm.27191

8. Adams N, Strauss M, Schluchter M, et al. Relation of measures of sleep-disordered breathing to neuropsychological functioning. $\mathrm{Am}$ J Respir Crit Care Med. 2001;163(7):1626-1631. doi:10.1164/ ajrccm.163.7.2004014

9. Vos T, Barker B, Begg S, et al. Burden of disease and injury in Aboriginal and Torres Strait Islander peoples: the indigenous health gap. Int J Epidemiol. 2009;38(2):470-477. doi:10.1093/ije/dyn240

10. Heraganahally S, Wasgewatta SL, McNamara K, et al. Chronic obstructive pulmonary disease in aboriginal patients of the Northern Territory of Australia: a landscape perspective. Int J Chron Obstruct Pulmon Dis. 2019;14:2205-2217. doi:10.2147/COPD.S213947

11. Randall DA, Lujic S, Havard A, et al. Multimorbidity among Aboriginal people in New South Wales contributes significantly to their higher mortality. Med J Aust. 2018;209(1):19-23. doi:10.5694/ mja17.00878. 
12. Kruavit A, Fox M, Pearson R, et al. Chronic respiratory disease in the regional and remote population of the Northern Territory Top End: a perspective from the specialist respiratory outreach service. Aust $J$ Rural Health. 2017;25(5):275-284. doi:10.1111/ajr.12349.

13. Bramley D, Hebert P, Jackson RT, et al. Indigenous disparities in disease-specific mortality, a cross-country comparison: New Zealand, Australia, Canada, and the United States. N Z Med J. 2004;117 (1207):U1215

14. Guglielmia O, Lanterib P, Garbarinoa S. Association between socioeconomic status, belonging to an ethnic minority and obstructive sleep apnea: a systematic review of the literature. Sleep Med. 2019;57:100-106. doi:10.1016/j.sleep.2019.01.042

15. Chen X, Wang R, Zee P, et al. Racial/ethnic differences in sleep disturbances: the Multi-Ethnic Study of Atherosclerosis (MESA). SLEEP. 2015;38(6):877-888. doi:10.5665/sleep.4732

16. Dudley KA, Patel SR. Disparities and genetic risk factors in obstructive sleep apnea. Sleep Med. 2016;18:96-102. doi:10.1016/j.sleep.20 15.01 .015

17. Mihaere KM, Harris R, Gander PH, et al. Obstructive sleep apnea in New Zealand Adults: prevalence and risk factors among Māori and Non-Māori. Sleep. 2009;32(7):949-956. doi:10.1093/sleep/32.7.949

18. Woods CE, Usher K, Maguire GP. Obstructive sleep apnoea in adult indigenous populations in high-income countries: an integrative review. Sleep Breath. 2015;19(1):45-53. doi:10.1007/s11325-0141032-7.

19. Woods CE, McPherson K, Tikoft E, et al. Sleep disorders in Aboriginal and Torres Strait Islander people and residents of regional and remote Australia. J Clin Sleep Med. 2015;11(11):1263-1271. doi: $10.5664 /$ jcsm. 5182

20. Heraganahally SS, Kruavit A, Oguoma VM, et al. Sleep apnoea among Australian Aboriginal and Non- Aboriginal patients in the Northern Territory of Australia- a comparative study. SLEEP. 2020;43(3):zsz248. doi:10.1093/sleep/zsz248.

21. Mehra S, Ghimire RH, Mingi JJ, et al. Gender differences in the clinical and polysomnographic characteristics among Australian aboriginal patients with obstructive sleep apnea. Nat Sci Sleep. 2020;12:593-602. doi:10.2147/NSS.S258330

22. Garg H, Er XY, Howarth T, et al. Positional sleep apnea among regional and remote Australian population and simulated positional treatment effects. Nat Sci Sleep. 2020;12:1123-1135. doi:10.2147/ NSS.S286403

23. Heraganahally SS, Kerslake C, Issac S, et al. Outcome of public hospital-funded continuous positive airway therapy device for patients with obstructive sleep apnoea: an Australian Perspective Study. Sleep Vigilance. 2020;4:195-204. doi:10.1007/s41782-02000114-4.

24. Heraganahally SS, Zaw KK, Tip S, et al. Obstructive sleep apnoea and adherence to continuous positive airway therapy among Australian women. Int Med J. 2020. doi:10.1111/imj.15076.

25. Johns M. A new method for measuring daytime sleepiness: the Epworth sleepiness scale. Sleep. 1991;14:540-545. doi:10.1093/ sleep/14.6.540

26. Bloch KE, Schoch OD, Zhang JN, et al. German version of the Epworth Sleepiness Scale. Respiration. 1999;66(5):440-447. doi:10.1159/000029408.

27. Vignatelli L, Plazzi G, Barbato A, et al. Italian version of the Epworth sleepiness scale: external validity. Neurol Sci. 2002;23 (6):295-300. doi:10.1007/s100720300004

28. Bajpai G, Shukla G, Pandey R, et al. Validation of a modified Hindi version of the Epworth Sleepiness Scale among a North Indian population. Ann Indian Acad Neurol. 2016;19(4):499-504. doi:10.4103/0972-2327.194427

29. Al-Abri M, Al-Hamhami A, Al-Nabhani H, Al-Zakwani I. Validation of the arabic version of the epworth sleepiness scale in oman. Oman Med J. 2013;28(6):454-456. doi:10.5001/omj.2013.126.
30. Zhang NJ, Peng B, Zhao T, Xiang M, Fu W, Peng Y. Modification of the Epworth Sleepiness Scale in Central China. Qual Life Res. 2011;20(10):1721-1726. doi:10.1007/s11136-011-9898-3.

31. Ghiassi R, Murphy K, Cummin A, Partridge M. Developing a pictorial Epworth Sleepiness Scale. Thorax. 2010;66(2):97-100. doi:10.1136/thx.2010.136879

32. Australian Bureau of Statistics. Estimates of Aboriginal and Torres Strait Islander Australians. Canberra, Australia: ABS; 2016.

33. Population - Australian Bureau of Statistics. Canberra: AUSSTATS; March 2020. Available from: www.abs.gov.au. Accessed February 15, 2021.

34. McMillan S, King M, Tully P. How to use the nominal group and Delphi techniques. Int J Clin Pharm. 2016;38:655-662. doi:10.1007/ s11096-016-0257-x.

35. Senaratna CV, English DR, Currier DC, et al. Sleep apnoea in Australian men: disease burden, co-morbidities, and correlates from the Australian longitudinal study on male health. BMC Public Health. 2016;16(Suppl 3):1029. doi:10.1186/s12889-016-3703-3708.

36. Adams RJ, Appleton SL, Taylor AW, et al. Sleep health of Australian adults in 2016: results of the 2016 Sleep Health Foundation national survey. Sleep Health. 2017;3(1):35-42. doi:10.1016/j.sleh.2016.11.005.

37. Woods C, Usher K, Kerr L, Ferns J, Maguire G. Barriers and Enablers to Successful Uptake of Continuous Positive Airway Pressure (CPAP) Treatment for Obstructive Sleep Apnoea for Aboriginal and Torres Strait Islander People. J Sleep Disord Treat Care. 2016;5(3):1-7. doi:10.4172/2325-9639.1000179.

38. Burns J, Thomson N. Summary of overweight and obesity among Indigenous peoples. Australian Indigenous Health Info Net; 2006. Available from: https://healthinfonet.ecu.edu.au/healthinfonet/getContent. php?linkid $=620387 \&$ title $=$ Summary + of + overweight + and + obesity + among +Indigenous+ peoples\&contentid=17506_1. Accessed January, 2017.

39. Cameron AJ, Zimmet PZ, Dunstan DW, et al. Overweight and obesity in Australia: the 1999-2000 Australian Diabetes, Obesity and Lifestyle Study (AusDiab). Med J Aust. 2003;178(9):427-432. doi:10.5694/j.1326-5377.2003.tb05283.x

40. Romero-Corral A, Caples SM, Lopez-Jimenez F, Somers VK. Interactions between obesity and obstructive sleep apnea. Implications for treatment. CHEST. 2010;137(3):711-719.

41. Indigenous peoples overview - World Bank Group. Available from: h t t p s : / / w w w. w o r ld b a n k. org/e n/to p i c/ indigenouspeoplesStateoftheWorld's. Accessed February 15, 2021.

42. Indigenous Peoples. Department of Economic and Social Affairs Division for Social Policy and Development Secretariat of the Permanent Forum on Indigenous Issues ST/ESA/328 United Nations publication. 2009: Sales No. 09.VI.13 ISBN 92-1-130283-7.

43. Heraganahally SS, Wasgewatta SL, McNamara K, et al. Chronic obstructive pulmonary disease with and without bronchiectasis in Aboriginal Australians - a comparative study. Intern Med J. 2020;50(12):1505-1513. doi:10.1111/imj.14718.

44. Schubert J, Kruavit A, Mehra S, et al. Prevalence and nature of lung function abnormalities among indigenous Australians referred to specialist respiratory outreach clinics in the Northern Territory. Intern Med J. 2019;49(2):217-224. doi:10.1111/imj.14112

45. Heraganahally SS, Howarth T, White E, et al. Lung function parameters among Australian Aboriginal "Apparently Healthy" Adults: an Australian Caucasian and Global Lung Function Initiative (GLI2012) various ethnic norms comparative study. Expert Rev Respir Med. 2020;23:1-11. doi:10.1080/17476348.2021.1847649.

46. Australian Bureau of Statistics. Australian Statistical Geography Standard (ASGS): Volume 5-remoteness structure, July 2011. ABS cat. no. 1270.0.55.005. Canberra: Australian Bureau of Statistics; 2013a.

47. Deloitte Access Economics. Re-awakening Australia: the economic cost of sleep disorders in Australia, 2010. Canberra, Australia: Deloitte Access Economics; 2011. Available from: http://www.slee phealthfoundation.org.au/pdfs/news/Reawakening\%20Australia.pdf. Accessed June, 2016. 
48. Heraganahally SS, White S. A cost-effective novel innovative box (C-Box) to prevent cockroach infestation of continuous positive airway pressure equipment: a unique problem in Northern Tropical Australia. Am J Trop Med Hyg. 2019;101(4):937-940. doi:10.4269/ajtmh.19-0434.

49. Van der Spuy I, Karunanayake CP, Dosman JA, et al. Determinants of excessive daytime sleepiness in two First Nation communities. $B M C$ Pulm Med. 2017;17:192. doi:10.1186/s12890-017-0536-x

50. Froese CL, Butt A, Mulgrew A, et al. Depression and sleep-related symptoms in an adult, indigenous, north american population. J Clin Sleep Med. 2008;4(4):356-361.

51. Gibson R, Gander P, Paine SJ, et al. Sleep of Māori and non-Māori of advanced age. N Z Med J. 2016;129(1436):52-61.

52. Yiallourou SR, Maguire GP, Carrington MJ. Sleep quantity and quality and cardiometabolic risk factors in Indigenous Australians. J Sleep Res. 2020. doi:10.1111/jsr.13067.

53. Deacon-Crouch M, Begg S, Skinner T. Is sleep duration associated with overweight/obesity in Indigenous Australian adults? $B M C$ Public Health. 2020;20:1229. doi:10.1186/s12889-020-09287-z.

54. Gentin N, Heraganahally S. Obstructive sleep apnoea in the Indigenous paediatric population in the northern territory. J Paediatr Child Health. 2020;56(S2):17-18. (ABSTRACT). doi:10. 1111/jpc.14901_8.

55. Netzer NC, Stoohs RA, Netzer CM, Clark K, Strohl KP. Using the Berlin questionnaire to identify patients at risk for the sleep apnea syndrome. Ann Intern Med. 1999;131(7):485-491. doi:10.7326/00034819-131-7-199910050-00002

56. Chai-Coetzer C, Hamilton S. Update on the assessment and investigation of adult obstructive sleep apnoea. Aust J Gen Pract. 2019;48 (4):176-181. doi:10.31128/AJGP-12-18-4777
57. Hamilton GS, Joosten SA. Obstructive sleep apnoea and obesity. Aust Fam Physician. 2017;46(7):460-463.

58. Senaratna CV, Perret JL, Lowe A, et al. Detecting sleep apnoea syndrome in primary care with screening questionnaires and the Epworth sleepiness scale. Med J Aust. 2019;211(2):65-70. doi:10.5694/mja2.50145.

59. Hesselbacher S, Subramanian S, Allen J, et al. Body mass index, gender, and ethnic variations alter the clinical implications of the epworth sleepiness scale in patients with suspected obstructive sleep apnea. Open Respir Med J. 2012;6:20-27. doi:10.2174/187430640 1206010020.

60. Silva GE, Vana KD, Goodwin JL, et al. Identification of patients with sleep disordered breathing: comparing the four-variable screening tool, STOP, STOP-Bang, and Epworth Sleepiness Scales. J Clin Sleep Med. 2011;7(5):467-472. doi:10.5664/JCSM.1308.

61. Oktay Arslan B, Uçar Hoşgör ZZ, Orman MN. Which screening questionnaire is best for predicting obstructive sleep apnea in the sleep clinic population considering age, gender, and comorbidities? Turk Thorac J. 2020;21(6):383-389. doi:10.5152/TurkThoracJ.20 19.19024.

62. Martynowicz H, Skomro R, Gać P, et al. The influence of hypertension on daytime sleepiness in obstructive sleep apnea. J Am Soc Hypertens. 2017;11(5):295-302. doi:10.1016/j.jash.2017.03.004.

\section{Publish your work in this journal}

Nature and Science of Sleep is an international, peer-reviewed, open access journal covering all aspects of sleep science and sleep medicine, including the neurophysiology and functions of sleep, the genetics of sleep, sleep and society, biological rhythms, dreaming, sleep disorders and therapy, and strategies to optimize healthy sleep.
The manuscript management system is completely online and includes a very quick and fair peer-review system, which is all easy to use. Visit http://www.dovepress.com/testimonials.php to read real quotes from published authors. 